\title{
Attitudes toward psychopharmacology among hospitalized patients from diverse ethno-cultural backgrounds Gabriel Thorens ${ }^{1}$, Marianne Gex-Fabry ${ }^{2}$, Daniele F Zullino ${ }^{1}$ and Ariel Eytan*3
}

Address: ${ }^{1}$ Department of Psychiatry, Division of Substance Abuse, University Hospitals of Geneva, Switzerland, ${ }^{2}$ Department of Psychiatry, Division of Adult Psychiatry, University Hospitals of Geneva, Switzerland and ${ }^{3}$ Department of Psychiatry, Division of Penitentiary Psychiatry, University Hospitals of Geneva, Switzerland

Email: Gabriel Thorens - Gabriel.Thorens@hcuge.ch; Marianne Gex-Fabry - Marianne.Gex-Fabry@hcuge.ch; Daniele F Zullino - Daniele.Zullino@hcuge.ch; Ariel Eytan* - Ariel.Eytan@hcuge.ch

* Corresponding author

Published: 9 July 2008

BMC Psychiatry 2008, 8:55 doi:10.1 186/147|-244X-8-55

This article is available from: http://www.biomedcentral.com/I47I-244X/8/55

(C) 2008 Thorens et al; licensee BioMed Central Ltd.

This is an Open Access article distributed under the terms of the Creative Commons Attribution License (http://creativecommons.org/licenses/by/2.0), which permits unrestricted use, distribution, and reproduction in any medium, provided the original work is properly cited.
Received: 7 January 2008

Accepted: 9 July 2008

\begin{abstract}
Background: Biological factors influencing individual response to drugs are being extensively studied in psychiatry. Strikingly, there are few studies addressing social and cultural differences in attitudes toward psychotropic medications. The objective of this study was to investigate ethnoculturally determined beliefs, expectations and attitudes toward medication among a sample of hospitalized psychiatric patients.
\end{abstract}

Methods: An ad hoc questionnaire was designed to assess patients' expectations, attitudes and prejudice toward medication. The study included 100 adult patients hospitalized in Geneva, Switzerland.

Results: Patients were in majority male (63\%), originated from Switzerland (54\%) and spoke the local language fluently (93\%). They took on the average 3 different psychotropic drugs. Sixty-eight percent of patients expected side effects and $60 \%$ were ready to stop medication because of them. Thirty percent of patients expected negative personal changes with treatment and $34 \%$ thought that their mental disorder could have been treated without drugs. Thirty six percent of the sample used alternative or complementary medicines. $35 \%$ of immigrant patients believed that medication had different effects on them than on local patients. When compared with Swiss patients, they more often reported that significant others had an opinion about medication $(p=0.04 \mathrm{I})$ and more frequently valued information provided by other patients about treatment $(p=0.010)$.

Conclusion: Patients' attitudes toward medication should be investigated in clinical practice, as specific expectations and prejudice exist. Targeted interventions, especially for immigrant patients, might improve adherence.

\section{Background}

Biological factors determining the effects of psychotropic medications are extensively studied for each drug category, both from pharmacokinetic and pharmacodynamic perspectives. The study of genetic variants influencing drug metabolism has developed more recently, through the emergence of pharmacogenetics [1]. This approach might permit to draw different metabolic profiles for different ethnicities and races, even though its clinical use is still limited [2,3]. More broadly, the utilization of genetic 
information to predict outcome of drug treatment, or pharmacogenomics, holds great promise for clinical psychiatry [4].

However, non-biological factors such as level of adherence to medication continue to impact profoundly upon treatment outcome [5]. Medication nonspecific therapeutic and adverse effects, respectively the placebo and nocebo phenomena, constitute important determinants of treatment outcome [6]. Social and ethno-cultural determinants of drug treatment outcome, such as patients' expectations and attitudes toward psychotropic medication, remain understudied. In other words, clinicians and researchers seem to pay more attention to the biological side of pharmacotherapy than to contextual issues [7]. Patients' expectations about treatment effects may be influenced by pill size, shape, and color, among other factors. The often cited study by Buckalew and Coffield showed that capsules were perceived as stronger than tablets, larger capsules were seen as stronger than smaller ones, and some capsule colors were specifically ascribed expectations about drug action [8]. Important inter-ethnic variations were demonstrated, e.g. Caucasians expected black capsules to be stimulant, while African-Americans expected them to be sedative [9]. In the present article, the term ethno-cultural is used in its broad definition and has to do with collective identity, i.e. the setting apart of one group of people from another on the basis of historical lineage, language, religion and membership of a community [10].

Ethno-cultural differences have repeatedly been found with regard to attribution of causes of various disorders (e.g. somatic vs. spiritual/divine). These "explanatory models of illness" are of special importance in mental health [11]. Eventually, culture influences representations, compliance, expectations about treatment and engagement with services [12].

Some psychometric instruments have been developed in order to analyze subjective parameters of pharmacotherapy. To our knowledge, these instruments took into consideration ethnic and cultural factors only marginally. For example, the widely used Drug Attitude Inventory (DAI), which was translated into several languages since its initial validation in the eighties, does not investigate ethnocultural aspects, neither in its shortened version (DAI-10), nor in its long version (DAI-30) [13]. Several other instruments exist, but they address exclusively psychotic disorders [14-16]. The aim of the present study was to contribute filling this gap and analyze cultural factors influencing attitudes toward psychotropic drug treatment in a multi-ethnic sample of psychiatric inpatients.

\section{Methods \\ Setting}

The study was conducted in one admission unit of the public psychiatric hospital in Geneva, an international, multicultural city of approximately 430'000 inhabitants located in the French speaking part of Switzerland. During the study period, the 15 to 18 -bed general psychiatry unit received patients with primary diagnoses of affective disorders $(33 \%)$, schizophrenia and other psychotic disorders (33\%), alcohol and other substance use disorders $(15 \%)$, personality disorders $(10 \%)$ and other disorders (9\%). During the 11-month recruitment period, a total of 400 patients were hospitalized in the unit (mean length of stay 14.4 days). All patients admitted to this unit and meeting inclusion criteria were individually approached. Inclusion criteria were sufficient length of stay to allow for psychiatric assessment (at least 2 days) and for partial remission of acute behavioral or psychotic symptoms. Patients who gave written informed consent were interviewed until 100 participants were recruited. Patients who did not provide informed consent did not differ clinically from those who gave consent. The study was approved by the local ethics committee.

\section{Questionnaire}

Taking into account a literature review about cultural considerations in non-biological issues affecting psychopharmacotherapy [17], we developed an ad hoc observerrating questionnaire. Three preliminary versions were pretested, thus permitting to reformulate or eliminate questions which were too difficult to understand or too vague. In its final version (available upon request), the questionnaire contained 22 items. Answers were rated on Likert scales (e.g. "not at all", "not really", "not sure", "rather yes", and "yes, very much"). For analysis, values were dichotomized by grouping the 3 former categories and the 2 latter ones, respectively. The following domains were investigated: personal opinion about drug aspect, administration mode and information about treatment, expected drug effects, use of alternative or complementary medicine and perceived influence of context and general attitude toward medication. Finally, four questions specifically addressed beliefs among immigrants to Switzerland.

Two experienced clinicians (a psychiatrist and a psychologist) conducted the interviews. Professional translators were used for patients who did not speak French, the local language.

\section{Patients}

One hundred hospitalized patients were included in the study (age range 19-65). Median length of stay was 7 days (range 2-67). Median number of prescribed drugs at the moment of the interview was 3 (range $0-10$ ). 
Patients were pooled into 3 groups according to their country of origin:

\section{(1) 54 patients originated from Switzerland}

(2) 25 patients came from a country that was part of the European Union (EU) (Italy $n=6$, Spain $n=6$, Portugal $n$ $=6$, France $n=5$, Greece $n=1$, UK $n=1$ )

(3) 21 patients came from non-EU countries (Turkey $n=$ 3, Zaire $\mathrm{n}=2$, Algeria, Angola, Bosnia, Brazil, Burundi, Cameroon, Chile, Congo, Morocco, Nigeria, Poland, Rumania, Rwanda, Senegal, Sudan, USA: $\mathrm{n}=1$ from each country). Poland and Rumania were not yet EU members at the time of the study.

The first group corresponds to patients sharing the local culture; the second group corresponds to patients that share some European ethno-cultural characteristics; the third group is composed of persons with very diverse ethno-cultural backgrounds.
Among subjects with a non-Swiss origin, 5 (10.9\%) were asylum-seekers, $3(6.5 \%)$ had a non-permanent residence permit (type B permit, valid for five years), 24 (52.2\%) had a permanent residence permit (type $\mathrm{C}$, with unrestricted access to labor market) and 13 (28.3\%) had become Swiss citizens.

Socio-demographic and treatment characteristics of participants are reported in Table 1.

\section{Statistical analysis}

The Fisher exact test for proportions was used for comparisons between groups, with significance level set at 0.05 (2-sided). Data were analyzed using the SPSS program, version 11 (SPSS Inc., Chicago IL, USA).

Results

Socio-demographic characteristics and current pharmacotherapy

As shown in Table 1, the 3 groups significantly differed with respect to religion, with Catholics over represented

Table I: Socio-demographic characteristics and current pharmacotherapy

\begin{tabular}{|c|c|c|c|c|c|c|c|}
\hline \multirow[b]{2}{*}{ Women } & \multicolumn{2}{|c|}{$\begin{array}{l}\text { Swiss } \\
(N=54)\end{array}$} & \multicolumn{2}{|c|}{$\begin{array}{c}\text { European } \\
\text { Union } \\
(\mathbf{N}=25)\end{array}$} & \multicolumn{2}{|c|}{$\begin{array}{l}\text { Others } \\
(\mathrm{N}=2 \mathrm{I})\end{array}$} & \multirow{2}{*}{$\begin{array}{c}\mathbf{P} \\
0.67\end{array}$} \\
\hline & 21 & $38.9 \%$ & 10 & $40.0 \%$ & 6 & $28.6 \%$ & \\
\hline Age $\geq 40$ years & 26 & $48.1 \%$ & 12 & $48.0 \%$ & 4 & $19.0 \%$ & 0.06 \\
\hline \multicolumn{8}{|l|}{ Religion } \\
\hline Catholic & 26 & $48.1 \%$ & 19 & $76.0 \%$ & 9 & $42.9 \%$ & 0.001 \\
\hline Protestant & 12 & $22.2 \%$ & 0 & $0.0 \%$ & 0 & $0.0 \%$ & \\
\hline Jewish & 0 & $0.0 \%$ & 0 & $0.0 \%$ & 0 & $0.0 \%$ & \\
\hline Muslim & 4 & $7.4 \%$ & 0 & $0.0 \%$ & 6 & $28.6 \%$ & \\
\hline Atheist & 8 & $14.8 \%$ & 4 & $16.0 \%$ & 2 & $9.5 \%$ & \\
\hline Other & 4 & $7.4 \%$ & 2 & $8.0 \%$ & 4 & $19.0 \%$ & \\
\hline \multicolumn{8}{|l|}{ French skills } \\
\hline Excellent & 54 & $100.0 \%$ & 22 & $88.0 \%$ & 17 & $81.0 \%$ & 0.006 \\
\hline Fair & 0 & $0.0 \%$ & 2 & $8.0 \%$ & 2 & $9.5 \%$ & \\
\hline Insufficient & 0 & $0.0 \%$ & 1 & $4.0 \%$ & 2 & $9.5 \%$ & \\
\hline \multicolumn{8}{|l|}{ Living status } \\
\hline Living alone & 26 & $48.1 \%$ & 9 & $36.0 \%$ & II & $52.4 \%$ & 0.74 \\
\hline Couple & 12 & $22.2 \%$ & 6 & $24.0 \%$ & 2 & $9.5 \%$ & \\
\hline Family & 11 & $20.4 \%$ & 8 & $32.0 \%$ & 6 & $28.6 \%$ & \\
\hline Institution & 5 & $9.3 \%$ & 2 & $8.0 \%$ & 2 & $9.5 \%$ & \\
\hline \multicolumn{8}{|l|}{ Education $(\mathrm{N}=99)$} \\
\hline None - elementary & 4 & $7.4 \%$ & I & $4.0 \%$ & 0 & $0.0 \%$ & 0.46 \\
\hline Compulsory education & 12 & $22.2 \%$ & 11 & $44.0 \%$ & 6 & $30.0 \%$ & \\
\hline Apprenticeship & 20 & $37.0 \%$ & 6 & $24.0 \%$ & 5 & $25.0 \%$ & \\
\hline College & 7 & $13.0 \%$ & 5 & $20.0 \%$ & 4 & $20.0 \%$ & \\
\hline Technical school & 6 & $11.1 \%$ & 1 & $4.0 \%$ & 1 & $5.0 \%$ & \\
\hline University & 5 & $9.3 \%$ & I & $4.0 \%$ & 4 & $20.0 \%$ & \\
\hline \multicolumn{8}{|l|}{ Current medication $(\mathrm{N}=95)$} \\
\hline Antipsychotics & 28 & $54.9 \%$ & 11 & $47.8 \%$ & 15 & $71.4 \%$ & 0.26 \\
\hline Antidepressants & 28 & $54.9 \%$ & 13 & $56.5 \%$ & 6 & $28.6 \%$ & 0.10 \\
\hline Mood stabilizers & 21 & $41.2 \%$ & 4 & $17.4 \%$ & 5 & $23.8 \%$ & 0.09 \\
\hline Tranquilizers & 18 & $35.3 \%$ & 10 & $43.5 \%$ & 6 & $28.6 \%$ & 0.63 \\
\hline Hypnotics & 20 & $39.2 \%$ & 5 & $21.7 \%$ & 8 & $38.1 \%$ & 0.34 \\
\hline
\end{tabular}


among patients from the EU, Protestants only represented among Swiss patients and the largest proportion of Muslims among non-EU subjects. Even though differences between groups were significant, a large majority of patients spoke French fluently in all 3 groups (> 80\%). There were no significant differences between groups with regard to prescribed psychotropic medication.

\section{Patient opinion about drug aspect, formulation and information}

A majority of patients rated the general aspect of the medication as important or very important. Taste was the specific aspect most often rated as important, followed by tablet size, shape, color, and package design. No significant difference was observed between patients of different origins (Table 2 ).

If they could choose the administration mode of their psychotropic treatment, most patients would prefer to take the drug orally. Only a minority of patients $(<30 \%)$ would select intravenous, intramuscular or subcutaneous administration (Table 2).

A large majority of patients $(\geq 90 \%)$, independently of their country of origin, would prefer to be informed about drug therapeutic and adverse effects by their attending physician. Information by nurses and written patient information were cited next. Interestingly, Swiss patients mentioned information from other patients significantly less often than foreigners (Table 2).

\section{Expected effects of medication and perceived influence of} ethno-cultural context

Sixty-eight percent of patients expected side effects and $60 \%$ thought that adverse effects might be severe enough to let them stop treatment. Thirty percent expected negative personal changes with treatment, whereas $62 \%$ expected positive changes. Thirty six percent of the sample used alternative or complementary medicines. While the opinion of significant others about treatment was more frequently cited among patients from foreign countries than from Switzerland, no difference was found for the possible interference between religious beliefs and treatment (Table 3).

\section{Patients' attitudes toward medication}

Thirty four percent of patients thought that their mental disorder could have been treated without drugs. Patients from non-European countries were significantly less often positive about taking medication than patients from the other two groups. However, in each group, a large majority of patients (>90\%) reported that they would probably

Table 2: Patients' opinion about drug aspect, formulation and information $\S$

\begin{tabular}{|c|c|c|c|c|c|}
\hline & $\begin{array}{c}\text { Total } \\
\text { sample } \\
(\mathbf{N}=92-100) *\end{array}$ & $\begin{array}{c}\text { Swiss } \\
(N=50-54) *\end{array}$ & $\begin{array}{c}\text { European } \\
\text { Union } \\
(\mathbf{N}=2 \mid-25) *\end{array}$ & $\begin{array}{c}\text { Others } \\
(\mathbf{N}=20-2 \text { I)* }\end{array}$ & $\mathbf{p}$ \\
\hline \multicolumn{6}{|c|}{ Are the following aspects of the drug important to you? } \\
\hline General aspect & $54.5 \%$ & $58.5 \%$ & $44.0 \%$ & $57.1 \%$ & 0.53 \\
\hline Taste & $56.0 \%$ & $51.9 \%$ & $56.0 \%$ & $66.7 \%$ & 0.53 \\
\hline Size & $46.0 \%$ & $46.3 \%$ & $44.0 \%$ & $47.6 \%$ & 1.00 \\
\hline Shape & $33.0 \%$ & $37.0 \%$ & $16.0 \%$ & $42.9 \%$ & 0.10 \\
\hline Color & $31.0 \%$ & $31.5 \%$ & $20.0 \%$ & $42.9 \%$ & 0.25 \\
\hline Package design & $26.0 \%$ & $31.5 \%$ & $8.0 \%$ & $33.3 \%$ & 0.047 \\
\hline \multicolumn{6}{|c|}{ If possible, would you select the following administration modes? } \\
\hline Tablets & $92.9 \%$ & $90.6 \%$ & $96.0 \%$ & $95.2 \%$ & 0.77 \\
\hline Effervescent tablets & $62.6 \%$ & $61.1 \%$ & $58.3 \%$ & $71.4 \%$ & 0.70 \\
\hline Drops & $45.9 \%$ & $45.3 \%$ & $50.0 \%$ & $42.9 \%$ & 0.89 \\
\hline Intravenous injection & $26.5 \%$ & $22.6 \%$ & $33.3 \%$ & $28.6 \%$ & 0.56 \\
\hline Intramuscular injection & $18.4 \%$ & $18.9 \%$ & $12.5 \%$ & $23.8 \%$ & 0.69 \\
\hline Subcutaneous injection & $16.5 \%$ & $23.1 \%$ & $12.5 \%$ & $4.8 \%$ & 0.15 \\
\hline \multicolumn{6}{|c|}{ From which sources do prefer to be informed about drug treatment? } \\
\hline Physician & $92.6 \%$ & $92.2 \%$ & $95.7 \%$ & $90.0 \%$ & 0.88 \\
\hline Nurse & $74.2 \%$ & $74.0 \%$ & $73.9 \%$ & $75.0 \%$ & 1.00 \\
\hline Written patient information & $74.2 \%$ & $80.4 \%$ & $59.1 \%$ & $75.0 \%$ & 0.17 \\
\hline Books, magazines & $32.6 \%$ & $32.0 \%$ & $31.8 \%$ & $35.0 \%$ & 1.00 \\
\hline Family, important others & $26.1 \%$ & $24.0 \%$ & $27.3 \%$ & $30.0 \%$ & 0.86 \\
\hline Television & $25.0 \%$ & $17.6 \%$ & $28.6 \%$ & $40.0 \%$ & 0.12 \\
\hline Other patients & $13.0 \%$ & $4.0 \%$ & $22.7 \%$ & $25.0 \%$ & 0.010 \\
\hline
\end{tabular}

* Missing values excluded from \% calculation.

$\S$ Percents refer to patients who answered "yes" or "yes, very much" 
Table 3: Expected effects of medication and perceived influence of ethno-cultural context $\S$

\begin{tabular}{|c|c|c|c|c|c|}
\hline & $\begin{array}{c}\text { Total } \\
\text { sample } \\
(\mathrm{N}=99-100) *\end{array}$ & $\begin{array}{l}\text { Swiss } \\
(N=54)\end{array}$ & $\begin{array}{c}\text { European } \\
\text { Union } \\
(\mathbf{N}=24-25)^{*}\end{array}$ & $\begin{array}{l}\text { Others } \\
(\mathrm{N}=2 \mathrm{I})\end{array}$ & $\mathbf{p}$ \\
\hline Do you expect side effects? & $68.0 \%$ & $66.7 \%$ & $60.0 \%$ & $81.0 \%$ & 0.29 \\
\hline Might these side effects be severe enough to let you interrupt the treatment? & $60.0 \%$ & $55.6 \%$ & $56.0 \%$ & $76.2 \%$ & 0.25 \\
\hline $\begin{array}{l}\text { Do you expect positive personal changes (character, personality ...) due to } \\
\text { pharmacotherapy? }\end{array}$ & $62.0 \%$ & $64.8 \%$ & $60.0 \%$ & $57.1 \%$ & 0.82 \\
\hline $\begin{array}{l}\text { Do you expect negative personal changes (character, personality ...) due to } \\
\text { pharmacotherapy? }\end{array}$ & $30.0 \%$ & $24.1 \%$ & $40.0 \%$ & $33.3 \%$ & 0.32 \\
\hline Do significant others have an opinion regarding your treatment? & $57.6 \%$ & $46.3 \%$ & $75.0 \%$ & $66.7 \%$ & 0.041 \\
\hline $\begin{array}{l}\text { Do you use alternative/complementary medicine (homeopathy, traditional medicine } \\
\text { etc.)? }\end{array}$ & $36.4 \%$ & $44.4 \%$ & $33.3 \%$ & $19.0 \%$ & 0.12 \\
\hline Does your physician's attitude influence treatment result? & $72.0 \%$ & $66.7 \%$ & $72.0 \%$ & $85.7 \%$ & 0.28 \\
\hline Does your nurses' attitude influence treatment result? & $69.0 \%$ & $66.7 \%$ & $60.0 \%$ & $85.7 \%$ & 0.14 \\
\hline Do your religious beliefs and practices interfere with treatment? & $9.0 \%$ & $5.6 \%$ & $16.0 \%$ & $9.5 \%$ & 0.32 \\
\hline
\end{tabular}

* Missing values excluded from \% calculation.

$\S$ Percents refer to patients who answered "yes" or "yes, very much"

or certainly continue to take the medication as prescribed after discharge from the hospital.

When compared with patients from EU-countries, subjects from non-European countries significantly more often thought that they received medication not available in their home country. While more than $80 \%$ of EUpatients believed that they would have the same reaction to medication as Swiss patients, this was the case for only $45 \%$ of non-European patients (Table 4 ).

\section{Discussion}

Globalization has led to a significant increase in migrations. People are now moving further, faster and in greater numbers than ever before [18]. This phenomenon impacts on psychiatric services. Several studies have indeed shown that patients consulting in western psychiatric facilities are increasingly multiethnic and multicultural [19]. In this context, it is important for caregivers to be aware of patients' attitudes toward treatments, as a form of cultural competence [20].

Table 4: Patients' attitudes toward medication $\S$

\begin{tabular}{|c|c|c|c|c|c|}
\hline & $\begin{array}{c}\text { Total } \\
\text { sample } \\
(\mathrm{N}=99-100)^{*}\end{array}$ & $\begin{array}{c}\text { Swiss } \\
(\mathrm{N}=53-54)^{*}\end{array}$ & $\begin{array}{c}\text { European } \\
\text { Union } \\
(\mathbf{N}=\mid 7-25)^{*}\end{array}$ & $\begin{array}{c}\text { Others } \\
(\mathrm{N}=|7-2|)^{*}\end{array}$ & $\mathbf{p}$ \\
\hline $\begin{array}{l}\text { Do you believe that you could have been treated } \\
\text { without medication? }\end{array}$ & $34.0 \%$ & $29.6 \%$ & $28.0 \%$ & $52.4 \%$ & 0.15 \\
\hline $\begin{array}{l}\text { Is your self image modified by the medication you } \\
\text { are taking? }\end{array}$ & $48.5 \%$ & $43.4 \%$ & $56.0 \%$ & $52.4 \%$ & 0.55 \\
\hline $\begin{array}{l}\text { What is your general opinion about taking medications? } \\
\text { (\% positive or very positive) }\end{array}$ & $59.0 \%$ & $68.5 \%$ & $64.0 \%$ & $28.6 \%$ & 0.007 \\
\hline $\begin{array}{l}\text { What is your general opinion about taking psychiatric } \\
\text { medications? (\% positive or very positive) }\end{array}$ & $44.0 \%$ & $51.9 \%$ & $40.0 \%$ & $28.6 \%$ & 0.19 \\
\hline $\begin{array}{l}\text { Are you going to take your medication as prescribed } \\
\text { after discharge from the hospital? (\% probably yes or yes) }\end{array}$ & $94.0 \%$ & $94.4 \%$ & $92.0 \%$ & $95.2 \%$ & 0.86 \\
\hline Do you consider all medications the same way? & $16.0 \%$ & $16.7 \%$ & $8.0 \%$ & $23.8 \%$ & 0.35 \\
\hline $\begin{array}{l}\text { Do you receive a treatment that you could not get in } \\
\text { your country of origin? }\end{array}$ & & & $17.6 \%$ & $58.8 \%$ & 0.032 \\
\hline $\begin{array}{l}\text { Could you receive, in your country of origin, } \\
\text { a treatment you do not get here? }\end{array}$ & & & $13.0 \%$ & $31.6 \%$ & 0.26 \\
\hline $\begin{array}{l}\text { Do you think you get the same treatment as a Swiss } \\
\text { patient? }\end{array}$ & & & $78.3 \%$ & $90.0 \%$ & 0.42 \\
\hline $\begin{array}{l}\text { Do you think you have the same reaction to } \\
\text { medication as a Swiss patient? }\end{array}$ & & & $82.6 \%$ & $45.0 \%$ & 0.013 \\
\hline
\end{tabular}

* Missing values excluded from \% calculation.

$\S$ Percents refer to patients who answered "yes" or "yes, very much", unless indicated otherwise 
To our knowledge, the present study is the first European survey examining differences of attitudes and beliefs toward psycho-pharmacotherapy in psychiatric patients from various ethno-cultural backgrounds. Our study confirms the importance given by patients to external characteristics of drugs, like taste and tablet size, and their preference for oral administration. There were few intercultural differences in this respect.

Physicians were clearly the preferred information source for the whole sample. Foreign patients tended to rely more on other patients on the ward as a source of information, compared with Swiss subjects. One possible explanation is that Swiss patients are more familiar with the local medical system and therefore accept therapeutic procedures more easily than foreign patients, the latter needing reassurance from experienced persons outside the medical staff. It could also be caused by insufficient or inadequate medical information given to foreign patients. The appropriate transmission of medical information is dependent on communication between staff and patient. Both profound cultural differences and insufficient use of trained interpreters can impede such communication in our local setting [21].

The opinion of relatives about treatment was cited more frequently by foreign patients than local patients. This could be due to differences regarding familial cohesion, which can be considered as traditionally stronger in Southern and Eastern countries than in Western Europe or the US. Indeed, migrants included in this study moved from collectivist (or socio-centric) societies to an individualistic (or ego-centric) one [22]. This finding could also reflect an increased need for peer support among people living in a foreign country.

The general opinion of non-European patients about taking medications was less often positive than among the European sub-groups. This result might reflect differences in diagnoses and/or cultural representations: Western medicines may be subject to different beliefs by different cultural groups, affecting their attitudes toward them [23]. Strikingly, more than $90 \%$ of all participants declared that they intended to take their medication as prescribed after discharge from the hospital. This result contrasts with adherence rates usually reported in the literature: rates of adherence for psychiatric illnesses are seldom above $65 \%$ and sometimes as low as 35\% [24]. Our result could reflect social desirability and willingness to appear adherent to treatment.

This study has several limitations. Firstly, country of origin was used as a proxy for ethno-cultural background. Place of birth and language spoken at home are more commonly accepted indicators [25]. However, since obtaining the Swiss nationality is a long and complicated process, we believe that most immigrants included in the study would have retained their nationality of origin. Secondly, attitudes toward medication were investigated from the patient's perspective only. It is however well known that patterns of prescription also vary with physicians' cultural stereotypes [26]. In the present study, although not statistically significant, non-European patients tended to receive more often antipsychotic medications and less often antidepressants than Swiss and European patients ( $\mathrm{p}=0.26$ and 0.10 respectively). Whereas these different prescription patterns might be associated with different distribution of diagnoses across groups, a cultural bias could also be invoked. Thirdly, other cultural factors that may influence preferences and attitudes toward treatment, such as spirituality, stigma or access to care [27], were not investigated. Fourthly, diagnoses were not recorded. However, we found no significant differences between patients treated with or without antipsychotic medication. This observation indicates that patients with a diagnosis of psychotic disorder, i.e. approximately one third of the sample, did not differ from patients with other diagnoses regarding attitudes toward medication. Fifthly, due to the absence of appropriate instruments in the literature, we used a non-validated questionnaire designed purposely for the study. Finally, the sample was too small to demonstrate subtle differences between the 3 different cultural groups.

\section{Conclusion}

Patients treated in a Swiss psychiatric hospital share most of their pharmacotherapy related attitudes and expectations independently of their region of origin. Medical staff members are the most trusted sources of information. However, there are some important differences between local and foreign patients. Results speak in favor of better integrating relatives of non-European patients in the therapeutic process. Sharing experiences, beliefs and expectations regarding treatment with other patients also appear to be of a special importance for foreign subjects. In order to improve adherence with treatment, these observations should be taken into account when organizing clinical services that serve culturally diverse populations.

\section{Competing interests}

The authors declare that they have no competing interests.

\section{Authors' contributions}

AE conceived the study and drafted the manuscript. GT coordinated the study and conducted some of the interviews. MGF participated in the design of the study and performed the statistical analysis. DFZ informed the discussion. 


\section{Acknowledgements}

The authors thank Mrs. Aynur Kir, psychologist, for conducting some of the interviews under the supervision of GT and AE.

\section{References}

I. $\mathrm{Ng} \mathrm{CH}$, Schweitzer I, Norman T, Easteal S: The emerging role of pharmacogenetics: implications for clinical psychiatry. Aust $N$ ZJ Psychiatry 2004, 38(7):483-489.

2. Jones DS, Perlis RH: Pharmacogenetics, race, and psychiatry: prospects and challenges. Harv Rev Psychiatry 2006, I 4(2):92-108.

3. Evans DA, McLeod HL, Pritchard S, Tariq M, Mobarek A: Interethnic variability in human drug responses. Drug Metab Dispos 2001, 29(4 Pt 2):606-610.

4. Pickar D, Rubinow K: Pharmacogenomics of psychiatric disorders. Trends Pharmacol Sci 200I, 22(2):75-83.

5. Osterberg L, Blaschke T: Adherence to medication. N Engl J Med 2005, 353(5):487-497.

6. Barsky AJ, Saintfort R, Rogers MP, Borus JF: Nonspecific medication side effects and the nocebo phenomenon. Jama 2002, 287(5):622-627.

7. Lin KM, Smith MW, Ortiz V: Culture and psychopharmacology. Psychiatr Clin North Am 200I, 24(3):523-538.

8. Buckalew LW, Coffield KE: An investigation of drug expectancy as a function of capsule color and size and preparation form. J Clin Psychopharmacol 1982, 2(4):245-248.

9. Buckalew LW, Coffield KE: Drug expectations associated with perceptual characteristics: ethnic factors. Percept Mot Skills 1982, 55(3 Pt I):915-9|8.

10. Kirmayer L]: Cultural psychiatry in historical perspective. In Textbook of cultural psychiatry Edited by: Bhugra D, Bhui K. Cambridge , Cambridge University Press; 2007.

II. Bhui K, Bhugra D: Explanatory models for mental distress: implications for clinical practice and research. $\mathrm{Br} J$ Psychiatry 2002, | 81:6-7.

12. Bhugra D: Severe mental illness across cultures. Acta Psychiatr Scand Suppl 2006:17-23.

13. Hogan TP, Awad AG, Eastwood R: A self-report scale predictive of drug compliance in schizophrenics: reliability and discriminative validity. Psychol Med 1983, I3(I): I77-183.

14. Kampman O, Lehtinen K, Lassila V, Leinonen E, Poutanen O, Koivisto A: Attitudes towards neuroleptic treatment: reliability and validity of the attitudes towards neuroleptic treatment (ANT) questionnaire. Schizophr Res 2000, 45(3):223-234.

15. Mantonakis J, Markidis M, Kontaxakis V, Liakos A: A scale for detection of negative attitudes towards medication among relatives of schizophrenic patients. Acta Psychiatr Scand 1985, 7 I(2): 186-189.

16. Thompson K, Kulkarni J, Sergejew AA: Reliability and validity of a new Medication Adherence Rating Scale (MARS) for the psychoses. Schizophr Res 2000, 42(3):24I-247.

17. Smith M, Lin KM, Mendoza R: "Nonbiological" issues affecting psychopharmacotherapy: cultural considerations. In Psychopharmacology and psychobiology of ethnicity Edited by: Spiegel D. Washington, DC , American Psychiatric Press; 1993.

18. Kelly B: Globalisation and psychiatry. Advances in Psychiatric Treatment 2003, 9:464-474.

19. Bhugra D: Migration and mental health. Acta Psychiatr Scand 2004, I 09(4):243-258.

20. Carpenter-Song EA, Schwallie MN, Longhofer J: Cultural competence reexamined: critique and directions for the future. Psychiatr Serv 2007, 58(10): | 362-1365.

21. Eytan A, Bischoff A, Loutan L: Use of interpreters in Switzerland's psychiatric services. J Nerv Ment Dis 1999, I 87(3): I90-192.

22. Bhugra D: Cultural identities and cultural congruency: a new model for evaluating mental distress in immigrants. Acta Psychiatr Scand 2005, I I I (2):84-93.

23. $\mathrm{Ng} \mathrm{CH}$, Klimidis $\mathrm{S}$ : Cultural factors and the use of psychotropic medications. In Ethno-psychopharmacology Edited by: $\mathrm{Ng} \mathrm{CH}$, Lin KM, BS S, E C. Cambridge , Cambridge University Press; 2008.

24. Cramer JA, Rosenheck R: Compliance with medication regimens for mental and physical disorders. Psychiatr Serv 1998, 49(2): |96-20|.

25. Escobar Jl, Vega WA: Mental health and immigration's AAAs: where are we and where do we go from here? J Nerv Ment Dis 2000, I 88( I I):736-740.
26. Opolka JL, Rascati KL, Brown CM, Gibson PJ: Ethnicity and prescription patterns for haloperidol, risperidone, and olanzapine. Psychiatr Serv 2004, 55(2): I 5 I-I56.

27. Cooper-Patrick L, Powe NR, Jenckes MW, Gonzales J], Levine DM, Ford DE: Identification of patient attitudes and preferences regarding treatment of depression. J Gen Intern Med 1997, I 2(7):431-438.

\section{Pre-publication history}

The pre-publication history for this paper can be accessed here:

http://www.biomedcentral.com/1471-244X/8/55/pre pub
Publish with Bio Med Central and every scientist can read your work free of charge

"BioMed Central will be the most significant development for disseminating the results of biomedical research in our lifetime. "

Sir Paul Nurse, Cancer Research UK

Your research papers will be:

- available free of charge to the entire biomedical community

- peer reviewed and published immediately upon acceptance

- cited in PubMed and archived on PubMed Central

- yours - you keep the copyright
BioMedcentral 